\title{
Physical and Textural Attributes of Freeze-Dried Genetically Modified and Non-Genetically Modified Soy Beans
}

\author{
Srinivas Rayaprolu ${ }^{1}$, Navam Hettiarachchy ${ }^{1, ~}$, Mohammed Aldoury ${ }^{1}$, Sungeun Cho ${ }^{1}$, \\ David Moseley ${ }^{2}$, Pengyin Chen ${ }^{2}$ \\ ${ }^{1}$ Department of Food Science, University of Arkansas, N Young Ave., Fayetteville, AR \\ ${ }^{2}$ Crop Soil and Environmental Sciences building, 115 Plant Sciences Building, University of Arkansas, Fayetteville, AR
}

\author{
Email address: \\ nhettiar@uark.edu (N. Hettiarachchy)
}

\section{To cite this article:}

Srinivas Rayaprolu, Navam Hettiarachchy, Mohammed Aldoury, Sungeun Cho, David Moseley, Pengyin Chen. Physical and Textural Attributes of Freeze-Dried Genetically Modified and Non-Genetically Modified Soy Beans. Journal of Food and Nutrition Sciences. Vol. 3, No. 3, 2015, pp. 119-125. doi: 10.11648/j.jfns.20150303.17

\begin{abstract}
Freeze-dried soybean snack foods are innovative and engage the nutritious whole soybean seeds in human diet. The freeze-dried soybeans provide high quality protein, cholesterol-free low percentage of saturated fats, minerals, and vitamins. Our research evaluated the quality of freeze-dried soybean seed products by testing their physical and textural properties. Seeds of six soybeans: R08-4004, R05-4969, R95-1705, Osage (4 non-genetically modified varieties), JYC-2 and UA Kirksey ( 2 genetically modified varieties) were cooked to prepare the freeze dried product. The physical characteristics such as color, water activity, water absorption efficiency, and textural characteristics including hardness and crunchiness were evaluated. The freeze-dried seeds showed significantly enhanced color and textural characteristics while maintaining crunchiness in the product along with low water activity. The water absorption efficiency increased with an increase in seed tissue integrity. The large sized seeds of genetically modified variety, JYC-2 (edamame or vegetable soybean) with high protein $(42 \%)$, were found to be best suited for preparing the snack or breakfast cereal. This study showed that freeze-drying the soybean seeds maintains the quality attributes and appeal after processing. The Acoustic Envelop Detector technique for measuring textural qualities demonstrated significant potential for comprehensive results and greater application in testing similar food products. Our findings suggest a higher prospective for the freeze-dried soybeans as snack food or breakfast cereal with an impending commercial value.
\end{abstract}

Keywords: Freeze-Dried Snack, Physico-Textural Properties, Genetically Modified Soybeans, Breakfast Cereal

\section{Introduction}

Soybean, Glycine $\max (\mathrm{L})$, cultivation gained popularity in the United States in the $20^{\text {th }}$ century due to its high quality protein and edible oil (Sullivan, 2005). According to the Food and Agriculture Organization of the United Nations soybeans have become a market-leading, highly traded commodity in the world (Harri et al., 2009). The harvested area under soybeans in 2013 was 30.6 million hectares in the U.S., which yielded 88.7 Metric Tons of soybean crop (Naeve et al., 2013). Edamame (vegetable soybean) has also been gaining importance in the U.S. due to the rising demand for its inclusion in the diet along with proliferation of the varieties grown and area cultivated (Sharma, 2013; Zhang \& Kyei-Boahen, 2005). According to the National Soybean Research Laboratory the abundance from soybean crop yield can be utilized in producing various food products including tofu, soy sauce, soy analogs, and soy snack foods (NSRL 1 and NSRL 2). These products completely or chiefly consist of soy ingredients that are rich in dietary fiber, isoflavones, proteins, vitamins and minerals. There has been a new trend in the markets to use soybeans as snack foods that are good for a healthy diet for children, as an ingredient in their several small meals during the day. They can also be included in the adult diet to help them regulate their digestive metabolism while providing high quality protein.

Studies have shown that $20 \%$ of the daily calories consumed by Americans are from snack foods. Using soybean as a snack food is an innovative approach to include these nutritious and healthful legumes into the consumers' 
diets. Soy snacks can serve vegans and vegetarians as a source of high quality vegetable protein. There are several health benefits from soybean snack foods due to the presence of high quality lipid and protein, low percentage of saturated fats, isoflavones as antioxidants, vitamins and minerals, and zero cholesterol (Friedman \& Brandon, 2001; McCue \& Shetty, 2004; Messina \& Lee, 2004). There are several methods to prepare snacks including roasting, vacuum microwave cooking, and freeze-drying. Although each method has both benefits and drawbacks, freeze-drying or lyophilization could be the most preferred method to produce snack foods, especially for the accrued nutritional benefits. The principle of freeze drying uses sublimation as a substitute for high temperatures to remove water. While freeze drying produces high quality products, application of heat in other methods affects the heat sensitive nutrients such as vitamins and other bioactive compounds. Freeze-drying has better effects on the textural properties of dried foods because it yields the lowest density $(\mathrm{g} / \mathrm{mL})$ and the highest rehydration rates compared to other drying methods (Lin et al., 1998). Freeze-drying also yields products with brighter appearance which enhances consumers' acceptability; while the products prepared using other heating processes appear darker due to the applied heat (González et al., 2003; Howard et al., 1996). The physical and textural properties of food products are of significant importance as they affect consumers' acceptance.

The main objective of the present investigation was to use the freeze-drying process to prepare a soybean snack food by including four non-genetically modified or non-GM soybeans, R95-1705, R08-4004, R05-4969, and Osage and two genetically modified or GM soybeans, JYC-2 (edamame) and UA Kirksey that are grown in the state of Arkansas, and to assess the physical and textural properties of the freezedried soybeans.

\section{Materials and Methods}

\subsection{Sample Preparation}

The soybean seeds from different varieties studied in this research were supplied by Dr. Pengyin Chen, a soybean breeder at the Department of Crop, Soil and Environmental Sciences, University of Arkansas (Fayetteville, AR, U.S.A.). The six varieties of soybean seeds were: R95-1705, R084004, R05-4969 and Osage (non-GM), and JYC-2 (Edamame) and UA Kirksey (GM). Seeds weighing $200 \mathrm{~g}$ from each variety were cleaned and soaked in water with a ratio of 1:4 (w/v) for 16 hours (overnight). The water was drained and the seeds were washed to remove any residual impurities before boiling in saline water $(1.5 \% \mathrm{w} / \mathrm{v})$ for 30 minutes. The cooked seeds were let to cool to ambient temperature and were frozen at $-25 \mathrm{C}$ in a blast freezer (Air-oChill, Electrolux Professional SpA., Pordenone, Italy) for 15 minutes. The frozen seeds were transferred into a freeze drier (Virtis Genesis, SP Scientific, PA, U.S.A.) with the condenser temperature set to $-45 \mathrm{C}$. A Leybold Trivac vacuum pump (A-Vac Industries, Anaheim, CA) was used to maintain a vacuum pressure of 230 to 250 Torr in the drying chamber. After four days (96 hours) the soybean seeds were taken out from the freeze drier, let to reach ambient temperature and transferred in to air-tight polyethylene storage bags.

\subsection{Measurement of Color Characteristics}

A color meter (CR-300 Minolta Co., Ltd. Osaka, Japan) was used to determine the color attributes, ' $\mathrm{L}^{*}$ ', ' $\mathrm{a}^{*}$ ', and ' $\mathrm{b}$ ', of both freeze-dried and unprocessed soybean seeds. ' $\mathrm{L}^{*}$ ' value is the measure of brightness/darkness, ' $\mathrm{a}$ ' indicates redness/greenness and ' $\mathrm{b}$ *' denotes blueness/yellowness. A white tile was used to standardize the devise before testing the samples for $\mathrm{L}^{*}, \mathrm{a}^{*}$, and $\mathrm{b}^{*}$ values (Hunter Lab, 2008). These values were measured in five replications for all the varieties of the freeze-dried soybean seeds. Other color attributes that were calculated based on $\mathrm{L}^{*}$, $a^{*}$, and $b^{*}$ measurements are Hue and Chroma. Hue is the attribute of colors that permits them to be classified as red, yellow, green, and blue or an intermediate between any adjacent pair of listed colors. Chroma is the quality of color that combines hue and saturation. The following equations were used for calculating the color attributes.

$$
\begin{aligned}
& \text { Hue }=\operatorname{arc} \operatorname{Tan}(\mathrm{a} / \mathrm{b}) \\
& \text { Chroma }=\sqrt{a^{2}+b^{2}}
\end{aligned}
$$

\subsection{Determination of Water Activity}

The Aqua Lab CX-2 water activity meter (Decagon Devices Inc., Pullman, WA, U.S.A.) was used to measure the water activity $\left(a_{w}\right)$, which is the ratio of vapor pressure of water against that of the food product. The soybean seeds were transferred as a single layer into a plastic container that is used to measure $a_{w}$ after inserting it into the chamber located on the device.

\subsection{Evaluation of Textural Characteristics}

Hardness and crunchiness of the freeze-dried soybean seeds were assessed using the texture analyzer (TA-XT2i, Stable Micro Systems Ltd, Godaming, Surrey, U.K.) equipped with the Acoustic Envelope Detector (Stable Micro Systems Ltd, Godaming, Surrey, U.K.) and a microphone (Model Em-501, YOGA Electronics Co., Ltd., Taipei City, Taiwan).

To minimize sample size/shape-induced variations in texture measurement, a set of five seeds of equal size from each variety were weighed and used for determining the textural characteristics. The five seed samples were placed on a load platform and a microphone was set $3 \mathrm{~cm}$ from the platform and with an angle of $0^{\circ}$ to the sample (Varela et al., 2006). The compression test was conducted in a silent laboratory at ambient temperature (approximately $23^{\circ} \mathrm{C}$ ) using a disc probe (diameter: $10 \mathrm{~cm}$ ) and the data acquisition rate was 500 points per second for both force and acoustic signals. The measurement of each sample was repeated 8 times. 


\subsection{Determination of Water Absorption Efficiency}

Ten grams each of both processed and unprocessed seeds from all the six varieties were separately weighed into 125 $\mathrm{mL}$ conical flasks. Hundred milliliters of deionized water was added and the seeds are allowed to soak for a specific period of time $(10,30,60$ and $120 \mathrm{~min})$. The samples were weighed after each absorption test period and water absorption efficiency was determined based on the differences in weights. The test was done in triplicates for the freeze dried seeds from all six soybean varieties.

\subsection{Statistical Analysis}

Data analysis was conducted using JMP Pro. 9.0 software (SAS Institute, Cary, NC, U.S.A.). A one-way analysis of variance (ANOVA) was used to analyze the significance of physical and textural characteristics among the six soybean samples. A statistically significant difference was defined as $P<0.05$. Post hoc comparisons were performed using Student's $t$-tests. The color and water absorption efficiency of the freeze dried seeds was compared to that of raw/ unprocessed seeds from the six varieties. The texture and water activity attributes of the freeze dried seeds were compared among the varieties.

\section{Results and Discussion}

\subsection{Color Characteristics}

Consumers' acceptance of food products depends on many attributes such as the appearance, texture, and flavor. Color is an important aspect of the appearance and is associated significantly with the acceptance of food products. Therefore, the effect of freeze-drying on the color of the soybean seeds was analyzed. The color was estimated by determining the $L^{*}, a^{*}, b^{*}$, Hue, and Chroma values. The values were compared with those of the unprocessed soybean seeds. Table 1 provides the values for the color characteristics of both the GM and non-GM, processed and unprocessed, soybean varieties.

Table 1. Color characteristics of the freeze-dried non-GM and GM soybean seeds.

\begin{tabular}{|c|c|c|c|c|c|c|}
\hline Varieties $^{\varnothing}$ & Type $^{\#}$ & $\mathbf{L}^{*}$ & $\mathbf{a}^{*}$ & $\mathbf{b}^{*}$ & Hue & Chroma \\
\hline \multirow{2}{*}{ JYC-2 } & $\mathrm{P}$ & $64.5 \pm 1.9^{\mathrm{bc}}$ & $0.8 \pm 0.5^{\mathrm{h}}$ & $16.0 \pm 2.2^{b}$ & $0.1 \pm 0.0^{\mathrm{f}}$ & $16.0 \pm 2.2^{\mathrm{bc}}$ \\
\hline & UP & $59.7 \pm 1.2^{\mathrm{f}}$ & $0.1 \pm 0.5^{\mathrm{i}}$ & $14.3 \pm 0.9^{c}$ & $0.0 \pm 0.0^{\mathrm{g}}$ & $14.3 \pm 0.9^{\mathrm{d}}$ \\
\hline \multirow{2}{*}{ UA Kirksey } & $\mathrm{P}$ & $69.5 \pm 2.2^{\mathrm{a}}$ & $1.4 \pm .3^{\mathrm{fg}}$ & $16.7 \pm 1.0^{\mathrm{ab}}$ & $0.1 \pm 0.0^{\mathrm{f}}$ & $16.7 \pm 1.0^{\mathrm{abc}}$ \\
\hline & UP & $62.1 \pm 1.6^{\mathrm{de}}$ & $3.1 \pm 0.4^{\mathrm{c}}$ & $16.2 \pm 0.8^{\mathrm{b}}$ & $0.2 \pm 0.0^{\mathrm{bc}}$ & $16.5 \pm 0.8^{\mathrm{abc}}$ \\
\hline \multirow{2}{*}{ R95-1705 } & $\mathrm{P}$ & $69.2 \pm 1.8^{\mathrm{a}}$ & $1.8 \pm 0.4^{\mathrm{ef}}$ & $15.1 \pm 0.6^{\mathrm{bc}}$ & $0.1 \pm 0.0^{\mathrm{e}}$ & $15.2 \pm 0.6^{\mathrm{cd}}$ \\
\hline & UP & $63.3 \pm 0.8^{\mathrm{cd}}$ & $3.6 \pm 0.3^{\mathrm{ab}}$ & $16.5 \pm 0.8^{\mathrm{ab}}$ & $0.2 \pm 0.0^{\mathrm{ab}}$ & $16.9 \pm 0.9^{\mathrm{ab}}$ \\
\hline \multirow{2}{*}{ R08-4004 } & $\mathrm{P}$ & $65.4 \pm 1.5^{\mathrm{b}}$ & $2.2 \pm 0.3^{\mathrm{de}}$ & $15.1 \pm 1.1^{\mathrm{bc}}$ & $0.1 \pm 0.0^{\mathrm{de}}$ & $15.3 \pm 1.1^{\mathrm{bcd}}$ \\
\hline & UP & $60.6 \pm 2.4^{\mathrm{ef}}$ & $3.2 \pm 0.4^{\mathrm{bc}}$ & $15.5 \pm 1.8^{\mathrm{bc}}$ & $0.2 \pm 0.0^{\mathrm{abc}}$ & $15.8 \pm 1.9^{\mathrm{bcd}}$ \\
\hline \multirow{2}{*}{ R05-4969 } & $\mathrm{P}$ & $69.7 \pm 1.7^{\mathrm{a}}$ & $1.3 \pm 0.3^{\mathrm{gh}}$ & $18.0 \pm 1.7^{\mathrm{a}}$ & $0.1 \pm 0.0^{\mathrm{c}}$ & $18.0 \pm 1.7^{\mathrm{e}}$ \\
\hline & UP & $62.4 \pm 0.7^{\text {cde }}$ & $3.6 \pm 0.3^{\mathrm{ab}}$ & $16.1 \pm 0.5^{\mathrm{b}}$ & $0.2 \pm 0.0^{\mathrm{f}}$ & $16.5 \pm 0.5 \mathrm{a}^{\mathrm{bc}}$ \\
\hline \multirow{2}{*}{ Osage } & $\mathrm{P}$ & $65.8 \pm 1.8^{\mathrm{b}}$ & $2.7 \pm 0.3^{\mathrm{cd}}$ & $15.2 \pm 1.6^{\mathrm{bc}}$ & $0.2 \pm 0.0^{\text {cd }}$ & $15.5 \pm 1.6^{\mathrm{bcd}}$ \\
\hline & UP & $61.6 \pm 0.4^{\text {def }}$ & $3.7 \pm 0.3^{\mathrm{a}}$ & $16.0 \pm 0.4^{\mathrm{b}}$ & $0.2 \pm 0.0^{\mathrm{a}}$ & $16.4 \pm 0.4^{\mathrm{abc}}$ \\
\hline
\end{tabular}

Values presented are mean \pm standard deviation of triplicate analysis and those connected with different letters (superscript) in each column are significantly different $(\mathrm{P}<0.05) .{ }^{\#} \mathrm{P}=$ freeze dried seeds; UP = raw or unprocessed seeds. ${ }^{\varnothing}$ Non-GM: R95-1705, R08-4004, R05-4969, Osage; GM: JYC-2, UA Kirksey.

The results show that the processed seeds are significantly brighter $(P<0.05)$ in color than the unprocessed seeds with higher ' $L *$ ' values among all the soybean varieties tested. The freeze-dried soybean seeds of three varieties, R95-1705, R05-4969 (non-GM) and UA Kirksey (GM) had brighter color in comparison to the other soybean varieties. The processed seeds had less redness (low ' $a$ *' value) than the unprocessed seeds among all the varieties tested. This may be due to the breakdown of carotenoids in the seed coat during processing. Two varieties, R05-4969 and JYC-2 showed significantly different $(P<0.05)$ and ' $b$ *' value for yellowness in comparison to the other soybean varieties. This is could be attributed to the green seed coat of JYC-2 (edamame) before processing and potentially the thickness of the seed coat protecting the color during processing in the R05-4969 variety.

The Hue values between the processed and unprocessed seeds were statistically different $(P<0.05)$ which is due to the cooking temperatures that altered the texture of the seed coat Freeze drying protected the modification in the Hue attribute of the seed coats. Furthermore, there were insignificant $(P<0.05)$ differences between the processed and the unprocessed seeds with respect to their yellowness and Chroma. The freeze-drying treatment enhanced the retention of color through sublimation process. This semipassive drying process gave distinct Chroma values that are statistically not significant among all varieties except R054969 (non-GMGM) variety $(\mathrm{P}<0.05)$. The difference in processed and unprocessed seeds for Chroma values were not significant for UA Kirksey (GM), R08-4004 and Osage (nonGM), while R95-1705, R05-4969 (non-GM) and JYC-2 (GM) showed significant differences between their processed and unprocessed seeds (Table 1). The effect of color saturation measured as Chroma was found to be significantly higher in 
R05-4969 among all the tested soybean varieties $(P<0.05)$. The freeze drying process provided significant protection to the color of the soybean seeds because there was no heat employed. Whereas, in other methods such as hot air drying and roasting big impacts on the color can be noticed including browning and decrease in brightness (Lin et al., 1998).

\subsection{Water Activity}

The total amount of free and bound water in any food is known as the water content of that food. Water activity is an indication of the free water available in foods, which is imperative in snack foods and cereals as it correlates to their crunchiness, a significant aspect of their textural quality (Heidenreich et al., 2004; Martinez-Navarraete et al., 2004; Mazumder et al., 2007). Water activity also dictates the shelf life of any food product as it correlates to the available free water that can promote microbial growth (Cheng-kuang et al., 2013). However, microorganisms differ in their requirements for water activity, and they range between 0.91 in food spoilage bacteria to 0.8 in spoilage molds. As a result, water activity not only controls the growth of microorganisms but also specifies which species will thrive well (Enfors, 2008; Reddy, 2007).

Water activity of the freeze dried soybean seeds were measured as five replications and the mean value was used to compare among the varieties. Table 2 shows the results of $a_{w}$ measurements for the freeze-dried soybean varieties. The $a_{w}$ among the tested freeze dried seeds ranged between 0.1 and 0.2 which is considered extremely low.

Table 2. Water activity $\left(a_{w}\right)$ of the freeze-dried soybean (six varieties) measured at $23^{\circ} \mathrm{C}$.

\begin{tabular}{ll}
\hline Varieties $^{\varnothing}$ & $\mathbf{a}_{\mathbf{w}}$ \\
\hline JYC-2 & $0.1 \pm 0.0^{\mathrm{b}}$ \\
UA Kirksey & $0.2 \pm 0.0^{\mathrm{a}}$ \\
R95-1705 & $0.2 \pm 0.0^{\mathrm{a}}$ \\
R08-4004 & $0.2 \pm 0.0^{\mathrm{a}}$ \\
R05-4969 & $0.2 \pm 0.0^{\mathrm{a}}$ \\
Osage & $0.2 \pm 0.0^{\mathrm{a}}$ \\
\hline
\end{tabular}

Values presented are mean \pm standard deviation of triplicate analysis and those connected by the same letter (superscript) in each column are not significantly different $(\mathrm{P}<0.05)$. ${ }^{\varnothing}$ Non-GM: R95-1705, R08-4004, R05-4969, Osage; GM: JYC-2, UA Kirksey.

The JYC-2 edamame variety had the largest seed size but lowest $\mathrm{a}_{\mathrm{w}}$ of 0.1 among the soybean varieties tested. Such low water activity is indicative of negligible enzymatic activity that inhibits formation of undesirable flavor compounds during storage (MacLeod et al., 1988; TorresPenaranda et al., 2006). Foods that have $\mathrm{a}_{\mathrm{w}}$ of 0.85 and-below are considered non-hazardous because most pathogenic bacteria cannot grow under such conditions (Dilbaghi \& Sharma, 2007). Since the freeze dried soybeans have lower water activity and possible zero microbial growth, there is a potential for a significantly longer shelf life.

\subsection{Textural Characteristics}

Texture characteristics play an important role in modulating consumers' acceptability for snack foods (Bourne, 2002). Hardness and crunchiness of freeze-dried soybeans were measured using the texture analyzer. The hardness was assessed as the energy needed to fracture the seeds while the crunchiness of the seeds was measured by the Acoustic Envelope Detector since the comprehension of crunchiness was linked to the auricular senses (Drake, 1963; Vickers \& Bourne, 1976; Szczesniak, 1988).

Table 3. Crunchiness and hardness (mean \pm standard deviation) of the freeze-dried soybean seeds (six varieties).

\begin{tabular}{llc}
\hline Varieties $^{\varnothing}$ & Crunchiness $^{1}$ & Hardness $^{2}$ (N x sec) \\
\hline JYC-2 & $132.9 \pm 16.8^{\mathrm{c}}$ & $260.7 \pm 43.1^{\mathrm{b}}$ \\
UA Kirksey & $124.3 \pm 13.0^{\mathrm{c}}$ & $244.1 \pm 54.7^{\mathrm{b}}$ \\
R95-1705 & $240.3 \pm 19.2^{\mathrm{a}}$ & $281.3 \pm 54.4^{\mathrm{b}}$ \\
Osage & $262.5 \pm 30.4^{\mathrm{a}}$ & $396.3 \pm 74.8^{\mathrm{a}}$ \\
R05-4969 & $187.9 \pm 29.1^{\mathrm{b}}$ & $420.2 \pm 92.8^{\mathrm{a}}$ \\
R08-4004 & $132.9 \pm 17.9^{\mathrm{c}}$ & $253.5 \pm 58.6^{\mathrm{b}}$ \\
\hline
\end{tabular}

${ }^{1}$ Crunchiness was determined by the number of peaks of the sound plot acquired from Acoustic Envelope Detector. ${ }^{2}$ Hardness was determined by the area of the force curve. Values presented are mean \pm standard deviation and those connected by the same letter (superscript) in each column are not significantly different $(\mathrm{P}<0.05)$. ${ }^{\varnothing}$ Non-GM: R95-1705, R08-4004, R05-4969, Osage; GM: JYC-2, UA Kirksey.

Table 3 shows significant differences in the crunchiness and hardness among the different varieties. The Osage and R95-I704 seeds showed highest crunchiness values among all the varieties with no significant difference. The freeze dried seeds from R08-4004 non-GM variety had similar crunchiness in comparison to that of GM varieties, JYC_2 and UA Kirksey $(P<0.05)$. The seeds of R05-4969 showed highest hardness among all the freeze dried seed samples (Table 3). The seeds of GM soybeans, UA Kirksey and JYC2 showed similar crunchiness and hardness which were not significantly different from that of two non-GM varieties: R95-1705 and R08-4004 $(P<0.05)$. Hence, the differences in the genetic nature of these seeds, GM or non-GM, did not impact the textural properties of the processed (freeze dried) soybean snack.

\subsection{Water Absorption Efficiency}

The freeze-dried soybean seeds can be consumed as a snack food or cereals. Since breakfast cereals are most commonly consumed with milk, water absorption ability of the freeze-dried seeds was determined and compared with that of unprocessed seeds. Water absorption is important for dry seed products, especially for ingredients in breakfast cereals since most people add milk before consumption. The water absorption ability of the freeze-dried soybean seeds was determined as the difference in weight before and after soaking in water (for specified period) and also compared to that of weight gained by unprocessed seeds after soaking for 
the same amount of time. Table 4 shows the results of the water absorption test for all the six varieties of soybeans (both processed and unprocessed). The freeze-dried seeds showed significantly higher water absorption ability than the unprocessed GM and non-GM soy varieties. This is perhaps associated with lower water content of the freeze-dried seeds due to disrupted cell membranes and walls during the cooking process that affected their permeability. It could also be due to the soaking and cooking steps during processing that affected the seed coat of the freeze dried seeds (Williams, 1983).

Table 4. Water Absorption efficiency of the six soybean varieties (processed and unprocessed).

\begin{tabular}{|c|c|c|c|c|c|c|}
\hline \multirow{2}{*}{ Varieties $^{\varnothing}$} & \multirow{2}{*}{ Type } & Original & \multirow{2}{*}{$10 \mathrm{~min}$} & \multirow{2}{*}{$30 \mathrm{~min}$} & \multirow{2}{*}{$60 \mathrm{~min}$} & \multirow{2}{*}{$120 \mathrm{~min}$} \\
\hline & & weight & & & & \\
\hline \multirow{2}{*}{ JYC-2 } & Processed & $10.0 \pm 0.0$ & $21.5 \pm 0.4^{\mathrm{a}}$ & $24.1 \pm 0.5^{\mathrm{a}}$ & $25.8 \pm 0.5^{\mathrm{a}}$ & $27.2 \pm 0.5^{\mathrm{a}}$ \\
\hline & Unprocessed & $10.0 \pm 0.0$ & $12.2 \pm 0.4^{\mathrm{f}}$ & $13.9 \pm 0.4^{\mathrm{f}}$ & $15.1 \pm 0.2^{\mathrm{f}}$ & $16.0 \pm 0.2^{\circ}$ \\
\hline \multirow{2}{*}{ UA Kirksey } & Processed & $10.0 \pm 0.0$ & $18.6 \pm 0.3^{\mathrm{b}}$ & $20.7 \pm 0.3^{\mathrm{c}}$ & $22.1 \pm 0.3^{\mathrm{c}}$ & $23.6 \pm 0.2^{c}$ \\
\hline & Unprocessed & $10.0 \pm 0.0$ & $12.1 \pm 0.5^{\mathrm{fg}}$ & $13.7 \pm 0.6^{\mathrm{f}}$ & $15.0 \pm 0.8^{\mathrm{f}}$ & $16.8 \pm 1.0^{c}$ \\
\hline \multirow{2}{*}{ R08-4004 } & Processed & $10.0 \pm 0.0$ & $17.4 \pm 0.2^{\mathrm{cd}}$ & $20.1 \pm 0.3^{\mathrm{d}}$ & $21.9 \pm 0.1^{\mathrm{cd}}$ & $23.6 \pm 0.1^{\circ}$ \\
\hline & Unprocessed & $10.0 \pm 0.0$ & $12.0 \pm 0.5^{\mathrm{fg}}$ & $13.5 \pm 0.4^{\mathrm{f}}$ & $14.6 \pm 0.6^{\mathrm{f}}$ & $16.3 \pm 0.8^{\mathrm{c}}$ \\
\hline \multirow{2}{*}{ R05-4969 } & Processed & $10.0 \pm 0.0$ & $18.9 \pm 0.4^{\mathrm{b}}$ & $21.5 \pm 0.5^{b}$ & $23.5 \pm 0.5^{\mathrm{b}}$ & $25.1 \pm 0.4^{b}$ \\
\hline & Unprocessed & $10.0 \pm 0.0$ & $13.1 \pm 0.3^{\mathrm{e}}$ & $14.8 \pm 0.3^{\mathrm{e}}$ & $16.2 \pm 0.3^{\mathrm{e}}$ & $18.0 \pm 0.5^{\mathrm{c}}$ \\
\hline \multirow{2}{*}{ Osage } & Processed & $10.0 \pm 0.0$ & $17.5 \pm 0.2^{\mathrm{c}}$ & $19.8 \pm 0.3^{\mathrm{d}}$ & $21.5 \pm 0.2^{\text {cd }}$ & $22.9 \pm 0.1^{\circ}$ \\
\hline & Unprocessed & $10.0 \pm 0.0$ & $12.2 \pm 0.1^{\mathrm{fg}}$ & $13.8 \pm 0.1^{\mathrm{f}}$ & $15.1 \pm 0.4^{\mathrm{f}}$ & $16.9 \pm 0.5^{\mathrm{c}}$ \\
\hline
\end{tabular}

Values presented are mean \pm standard deviation of triplicate analysis. Values connected by the same letter (superscript) in each column are not significantly different $(\mathrm{P}<0.05) .{ }^{\#}$ Processed $=$ freeze-dried seeds; Unprocessed $=$ raw seeds. ${ }^{\varnothing}$ Non-GM: R95-1705, R08-4004, R05-4969, Osage; GM: JYC-2, UA Kirksey.

The results also revealed that JYC-2 edamame variety has the highest water absorption ability among the processed seeds, which may be attributed to its large seed size and lowest $\mathrm{a}_{\mathrm{w}}$. On the other hand, the R05-4969 variety showed highest water absorption among the unprocessed seeds $(\mathrm{P}<$ 0.05). It was clear that the water absorption rate was higher in the first 10 min of soaking than the latter periods which agrees with previous studies conducted by Lin et al., (1998).

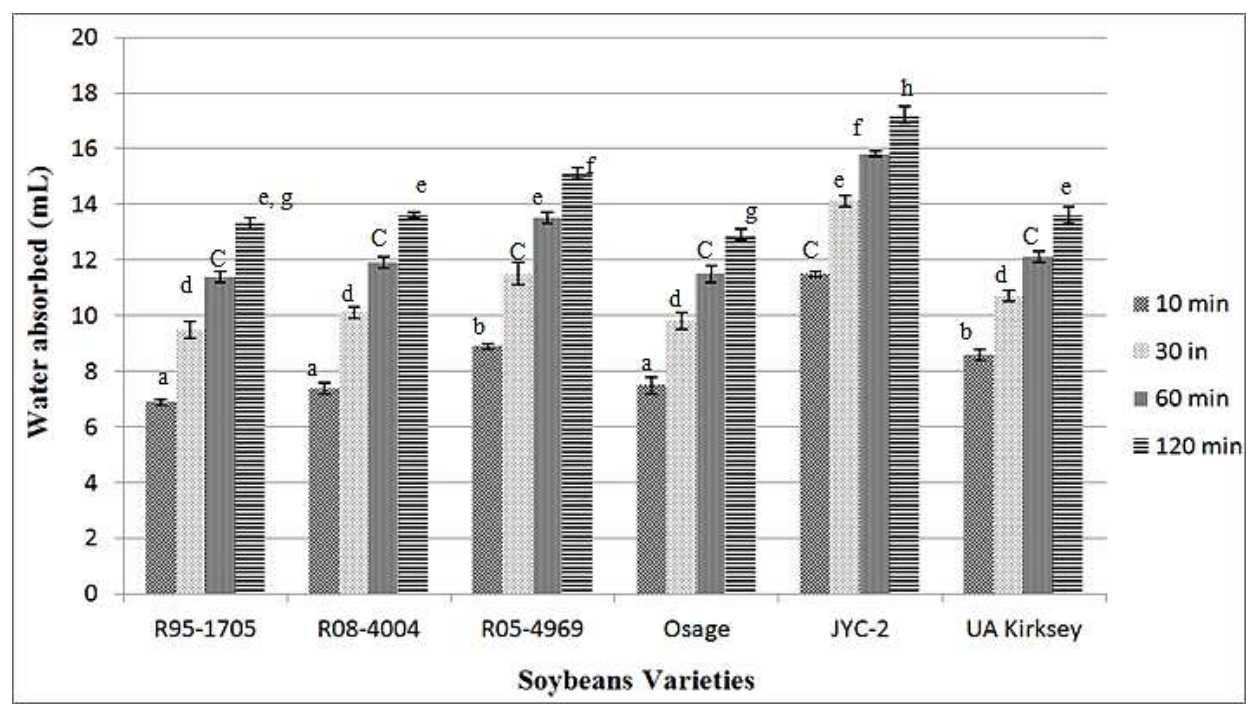

Figure 1. Amount of water absorbed by the freeze dried soybeans (GM and non-GM) seeds over the soaking time. Bars represent means of amount of water absorbed over soaking time $(10,30,60$ and 120min) and the error bars represent the standard deviations. Bars connected by same letter are not significantly different from each other (P<0.05). "Non-GM: R95-1705, R08-4004, R05-4969, Osage; GM: JYC-2, UA Kirksey.

The amount of water absorbed (in $\mathrm{mL}$ ) by the six freezedried soybeans over the two hour soaking time period is shown in Figure 1 which shows the variation among the varieties. High amount of water was absorbed by JYC-2 among all the six soybean varieties which correspond to the large seed size. The freeze dried seeds of R05-4969 showed the next highest absorption of water. UA Kirksey, R95-1705 and R08-4004 showed comparable water absorption trends while Osage soaked the lowest amount of water during the test. The results of this test reveal that the high water absorption ability of freeze-dried seeds will have a prominent influence on incorporation of freeze dried soybeans in to breakfast cereals or as snack foods. 


\section{Conclusion}

This study is the first of its kind that demonstrated the use of freeze-drying process to produce snack foods or breakfast cereals from GM and non-GM soybean varieties with high product quality in term of both physical and textural attributes. The results from all the tests for the quality attributes showed that the freeze-dried products have brighter color, better water absorption characteristics, significant textural character and lowest water activity. The genotype of the soybean varieties had no significant effect on the quality attributes during or after processing in preparation of the snack product. These beneficial attributes add to the nutritional value of soybeans and have significantly higher values in comparison to the products prepared using methods that use heat during processing. Further studies will include consumer acceptability and marketability of the freeze-dried soybean snack products.

\section{Acknowledgements}

The authors would like to thank the Arkansas Soybean Promotion Board for providing the funds to conduct this project. The authors would also like to thank Dr. Han-Seok Seo, University of Arkansas, for his help in the textural quality analysis.

\section{References}

[1] Bourne M. C. (2002). Food texture and viscosity: Concept and measurement, 2nd ed., New York State Agricultural Experiment Station and Institute of Food Science. Cornell University, Geneva, New York, pp.171-189.

[2] Cheng-Kuang H., Wei-Hsuan L. and Huai-Wen Y. (2013). Influence of preheating on antioxidant activity of the water extract from black soybean and color and sensory properties of black soybean decoction. Journal of the Science of Food and Agriculture, 93(15), 3883-3890.

[3] Dilbaghi N. and Sharma S. (2007). Food and industrial microbiology: Food spoilage, food infections and intoxications caused by microorganisms and methods for their detection. Retrieved from http://www.researchgate.net/profile/Neeraj_Dilbaghi/publicati on $/ 237395310$

_Food_spoilage_food_infections_and_intoxications_caused_b y_microorganisms_and_methods_for_their_detection/file/9c9 $6052 \mathrm{~d} 276 \mathrm{a} 081 \mathrm{f} 7 \mathrm{e} . \mathrm{pdf}$

[4] Drake B. K. (1963). Food crushing sounds. An introductory study. Journal of Food Science, 28, 233-241.

[5] Enfors S.-O. (2008). Food microbiology (pp. 10-11). KTH Biotechnology. Stockholm. Retrieved from http://www.biotech.kth.se/bioprocess/enfors/Downloads/Food Microbiology .pdf

[6] Friedman M. and Brandon D. L. (2001). Nutritional and Health Benefits of Soy Proteins. Journal of Agricultural Food Chemistry, 49(3), 1069-1086.
[7] González M., Gallego M. and Valcárcel M. (2003). Liquid Chromatographic Determination of Natural and Synthetic Colorants in Lyophilized Foods Using an Automatic SolidPhase Extraction System. Journal of Agricultural Food Chemistry, 51(8), 2121-2129.

[8] Harri A., Nalley L. and Hudson D. (2009). The Relationship between Oil, Exchange Rates, and Commodity Prices. Journal of Agricultural and Applied Economics, 41(2), 501-510.

[9] Heidenreich S., Jaros D., Rohm R. and Ziems A. (2004). Relationship between water activity and crispiness of extruded rice crisps. Journal of Texture Studies, 35, 621-633.

[10] Howard L. R., Braswell D. D. and Aselage J. (1996). Chemical composition and color of strained carrots as affected by processing. Journal of Food Science, 61, 327-330.

[11] HunterLab. (2008). "Hunter L, a, b Color Scale." HunterLab. http://www.hunterlab.com/appnotes/an08_96a.pdf (accessed October 13, 2011).

[12] Lin T. M., Durance T. D. and Scaman C. H. (1998). Characterization of vacuum microwave, air and freeze dried carrot slices. Food Research International. 31, 111-117.

[13] MacLeod G., Ames J. and Betz N. L. (1988). Soy flavor and its improvement. Critical Reviews in Food Science and Nutrition, 27(4), 219-400.

[14] Martinez-Navarraete N., Moragu G., Talens P. and Chiralt A. (2004).Water sorption and the plasticization effect in wafers. International Journal of Food Science and Technology, 39, $555-562$.

[15] Mazumder P., Roopa B.S. and Bhattacharya S. (2007). Textural attributes of a model snack food at different moisture contents. Journal of Food Engineering, 79, 511-516.

[16] McCue P. and Shetty K. (2004). Health Benefits of Soy Isoflavonoids and Strategies for Enhancement: A Review. Critical Reviews in Food Science and Nutrition, 44(5), 361-367.

[17] Messina M., Ho S. and Lee A. D. (2004). Skeletal benefits of soy isoflavones: a review of the clinical trial and epidemiologic data. Current Opinions in Clinical Nutrition and Metabolic Care, 7(6), 649-658.

[18] Naeve S. L., Orf J. H. and Weidenbenner N. H. (2013). United States Soybean Quality Annual Report. Retrieved from http://28vp741 fflb42av02837961yayh.wpengine.netdnacdn.com/wp-content/uploads/2012/09/2013-USSECCommodity-Soybean-Report.pdf

[19] Reddy G. (2007). Food industrial microbiology: Food as substrate for microorganisms. Dept. Microbiology. Osmania University-Hyderabad. Retrieved from http://nsdl.niscair.res.in/Jsp ui/bitstream/123456789/118/1/FoodasSubstrate.pdf

[20] Sharma K. P. (2003). Varietal Yield Stability and Appropriate Management for Quality Organic Edamame Production. Project report. Organic Sector Development Program (I-166). The Sharing Farm Society - Richmond Food Security Society. Nature's Path Foods. Retrieved from $\mathrm{http}: / /$ certifiedorganic.bc.ca/programs/osdp/I166_Edamame2_Final_Report. pdf

[21] Sullivan C. L. (2005). Soy on the menu recipes for foodservice. Illinois Center for Soy Foods. Retrieved from http://www.nsrl.illinois.edu/nutrition/multimedia/SoyOnMenu .pdf 
[22] Szczesniak A. (1988). The meaning of textural characteristicscrispiness. Journal of Texture Studies, 9, 51-59.

[23] The National Soybean Research Laboratory (1). (n. d.). A soy foods primer. Retrieved from http://www.nsrl.uiuc.edu/nutrition/multimedia/A\%20Soy\%20 Foods\%20Primer.pdf. Citation in the text: NSRL 1.

[24] The National Soybean Research Laboratory (2). (n. d.). Super soy snacks. Retrieved from http://www.nsrl.uiuc.edu/nutrition/multimedia/Super\%20Soy $\% 20$ Snacks.pdf. Citation in the text: NSRL 2.

[25] Torres-Penaranda A. V., Reitmeier C. A., Wilson L. A., Fehr W. R. and Narvel J. M. (2006). Sensory Characteristics of Soymilk and Tofu Made from Lipoxygenase-Free and Normal Soybeans. Journal of Food Science, 63(6), 1084-1087.
[26] Varela P., Chen J., Fiszman S. and Povey M. J. W. (2006). Crispiness assessment of roasted almonds by an integrated approach to texture description: texture, acoustics, sensory and structure. Journal of Chemometrics, 20, 311-320.

[27] Vickers Z. and Bourne M.C. (1976). A psycho-acoustic theory of crispiness. Journal of Food Science, 41, 1158-1164.

[28] Williams P. C., Nakoul H., and Singh K. B. (1983). Relationship between cooking time and some physical characteristics in chickpeas (Cicer arietinum L.). Journal of the Science of Food and Agriculture, 34(5), 492-496.

[29] Zhang L. and Kyei-Boahen S. (2007). Growth and Yield of Vegetable Soybean (Edamame) in Mississippi. Horticulture Technology Journal, 17(1), 26-31. 